\title{
The Design of Computer-Supported Collaborative Learning Environments in Higher Education
}

\author{
Begoña Gros, Vania Guerra and Javier Sánchez \\ University of Barcelona, Spain
}

\begin{abstract}
The main goal of this article is to analyze the implications of computer supported collaborative learning in higher education. To achieve this goal, we will describe the situation of the current research in this field and will focus our attention on the issues relating to the design of the conditions to promote collaborative processes and knowledge building. In the second part of the article, we will concentrate on the analysis of the results that we have obtained with the use of the programme Knowledge Forum as a support during the collaborative process in higher education.
\end{abstract}

Key words: Collaborative learning. Higher education. Information and communication technologies.

\section{RESUMEN}

El objetivo fundamental de este artículo es analizar las implicaciónes del aprendizaje colaborativo mediado en la enseñanza universitaria. Para alcanzar este objetivo, se realizará una descripción de la situación de las investigaciónes actuales en este ámbito enfatizando los aspectos relativos al diseño de las condiciónes para favorecer el proceso colaborativo y la construcción del conocimiento. En la segunda parte del artículo, nos centraremos en el análisis de los resultados obtenidos con el uso de la plataforma "Knowledge Forum" como apoyo al aprendizaje colaborativo en modalidades semipresenciales de la enseñanza universitaria.

Descriptores: Aprendizaje colaborativo. Educación superior. Nuevas technologías de la infomación y de la communicación.

RÉSUMÉ

Le but principal de cet article est d'analyser les implications de l'apprentissage collaboratif en éducation supérieure réalisé au moyen de l'informatique. Pour atteindre ce but nous allons décrire la situation de la recherche courante en ce domaine et centrer notre attention sur les questions relatives au design des conditions qui promeuvent le processus collaboratif et le développement du savoir. Dans la deuxième partie de l'article, nous concentrerons sur l'analyse des résultats que nous avons obtenus en utilisant le programme Knowledge Forum (le forum du savoir); titre de soutien au cours du processus collaboratif en éducation supérieure.

Motes-Clés: Apprentissage Collaboratif. Éducation supérieure. Le technologie de l'information. 


\section{Introduction}

$\mathrm{A}$ Ll Situations in eDUCATION are determined by many interconnecting variables that form a network which is invisible to the non-expert. For this reason, although we may all speak of education, of learning difficulties, and of teaching problems, we are in fact simply linking together small connections in this wider web. Education is a complex system and pedagogy needs to make itself responsible for understanding these hidden connections. (Capra 2002)

The information society has generated many connections that have far-reaching consequences both for our daily lives and for the carrying out of educational and professional tasks. Indeed, we find ourselves in a position today where everything needs to be considered afresh: the sources of our knowledge, models that generate content, research methods, relations with students, the role of the teacher, the technologies we ought to be using, etc. In short, the design of teaching-learning processes that were centred on the teacher-student-content triangle have become increasingly complex forming a vast web. Our present task is to make sense of this web and its connections and, consequently, to design environments that facilitate learning.

Higher education is not exempt from this task. Universities today are becoming increasingly interested in the quality of teaching and in the training of faculty teachers. This has come about largely because relationships between society, culture, and the university have gradually changed over the years.

In its origin, the university was the cradle of all major contributions to the sciences and culture. For many years the university was seen as the space dedicated to knowledge, and it enjoyed a virtual monopoly on the dissemination of the highest levels of learning to society. During the last century, various models of higher education have operated side by side, ranging from models centred on providing specialist knowledge to those that have preferred to provide a wider, more general education and training. Yet, whatever the model, the university is an institution that has continued to have a major influence on the development of knowledge.

However, the situation has changed notably. As Barnett claims, "higher education has gone from being an institution in society to being an institution of that society." (2001, 222) The university no longer holds a monopoly over expert knowledge. Knowledge has not only expanded to organizations outside the universities, but higher education is also being offered outside this domain.

The university is an institution of society, and the fact that today we speak of education in terms of competencies and credits - thereby shifting the emphasis away from the traditional teacher-focused class to the work of the student - represents a pragmatic and utilitarian attempt at adjusting to the new social situation and the requirements of the job market. We believe that there remains much to be done in terms of developing the function of the teacher so that it is more firmly based in encouraging the work and participation of students in seminars, projects, and the solving of problems, etc. Indeed, most teachers when asked about their work still speak above all about knowledge, preparing their classes, and, in the best of cases, of their concern for student interaction in these classes. (Gros-Romaña 2004) 
In short, the university has an educative responsibility. It remains as true today that a necessary condition for the transmission of cultural knowledge and for access to the culture in the university is that university teachers and students work together in contexts in which they share this knowledge. A further condition includes recognising the responsibility of the university to educate, which means not only presenting knowledge but also promoting channels for student access and responsible involvement with this world of knowledge, within situations that favour their critical participation and the development of their own thinking. The question we raise here is whether today the university is working in order to train persons who are adaptable to change, capable of understanding the provisional nature of knowledge, of working in collaboration, of thinking for themselves. A number of the changes that are now being introduced might facilitate the development of new methods of teaching that address some of these questions. It is here that new computer-supported tools used for the design of student-centred learning programmes might favour these processes.

\section{Computer-Supported Collaborative learning: A New paradigm?}

The term computer-supported collaborative learning (CSCL) was first used by Koschmann (1996), who defined this environment as a research space based on three theories: neo-Piagetian conflict theory, the historical-cultural theory and social practice theory. Subsequently, Koschmann (1999) was to add to these the theories of Dewey and Bakhtin as further important points of reference. In recent years, interest in computer-supported collaborative learning has grown. (Koschmann 1996) For many teachers and researchers, CSCL appears to be one of the most promising tools for bringing about change in teaching-learning practices.

Collaborative learning studies originated in research conducted into group learning and, in fact, as early as the 1980s studies involving this approach were being undertaken, although much more closely applied to the idea of cooperative work or working in small groups. The idea of collaboration as a basic form of human activity and of cultural development has though been present throughout the history of education and psychology. However, initially technological developments were not so concerned with social aspects of learning, emphasizing instead more individual aspects of learning.

In general, computer-supported collaborative learning expresses two important ideas: first, the idea of learning collaboratively, with others, in a group. In this sense, the learner is not seen as an isolated person but rather in interaction with others. It is based on the idea that sharing goals and distributing responsibilities are desirable forms of learning. Furthermore, it emphasizes the role of the computer as an element that intervenes in this process. It is therefore a process where the individual learns to collaborate and collaborates in order to learn.

In 1996, when Koschmann recognised CSCL as an emerging paradigm in educational technology, much research was set in motion. The short history of CSCL shows that different interpretations of CSCL already exist and that various meanings are 
attached to it. For example, Koschmann (1999) refers to CSCL as collaboration and learning, suggesting that we should focus our attention on researching the link between learning and work. In contrast, Dillenbourg (1999) highlights the importance of the element of collaboration differentiating it from working cooperatively. Pea (1996) refers to aspects of coordination between the collective and the cooperative. Roschelle and Teasley (1995) stress the role of shared knowledge and consider that collaboration is a "coordinated, synchronous activity that is the result of a continued attempt to construct and maintain a shared conception of the problem." $(1995,70)$

Many of the practices derived from these approaches have led to the recovery of some of the postures previously developed in pedagogy and, in particular, the educational approaches defended by Dewey at the beginning of the twentieth century. This recovery is currently occurring as part of what is known as situated cognition. This theory takes as its point of reference the works of Vygotsky and those of other authors including Leontiev (1978) and Luria (1987) and more recently of Rogoff (1993), Lave (1997), Bereiter (1997), Engeström and Cole (1997), and Wenger (2001), to mention just a few of the better known studies in the field of education. Situated cognition takes on different forms and names, directly linked with concepts such as situated learning, legitimate peripheral participation, cognitive apprenticeship and distributed cognition.

The theoreticians of situated learning base their arguments on the premise that knowledge is situated, that it is a part and a product of the activity, the context and the culture in which it is developed and used. This relatively new view has led to an instructional approach - situated teaching - which stresses the importance for learning of the activity and the context and recognises that schooling is, above all, a process of culturalization in which the pupils are gradually integrated into a community or culture of social practices. Similarly, the idea is held that learning and doing are inseparable actions. And consequently, a basic principle of this approach is that the students should learn in the appropriate context. The design of learning contexts has become one of the main tasks for the teacher, with the result that the role of the teacher has changed markedly.

Despite the fact that the theories concerning collaborative learning and knowledge construction have a number of points in common, a range of different perspectives exist concerning the process of knowledge construction and the means of intervening to promote it. In this sense, we can distinguish three types of foci: learning as acquisition, as participation and as knowledge creation (Table 1).

The idea of the learner as a receptacle presents learning as a process of construction and acquisition, and the results of the process are apparent in the transfer of this knowledge, that is, the capacity to use and apply knowledge in new situations. Knowledge is seen as a property and possession of the individual mind.

By contrast, if we consider the perspective adopted in situated participation and knowledge, emphasis is given to the fact that cognitive activities are always determined by a social and cultural context which cannot be understood in isolation. (Brown, Collins, Duguid 1989; Lave-Wenger 1991) Our activities and settings, in a context of participation, are seen as parts of the mutual construction of the whole. The mind- 
Table 1

\begin{tabular}{llll}
\hline & Acquisition & Participation & Knowledge Creation \\
\hline Focus of education & Specific knowledge & $\begin{array}{l}\text { Culturalization, } \\
\text { development of } \\
\text { identity }\end{array}$ & $\begin{array}{l}\text { Construction of know- } \\
\text { ledge, extending learning, } \\
\text { innovation }\end{array}$ \\
\hline Theory & $\begin{array}{l}\text { Theories of know- } \\
\text { ledge, outlines } \\
\text { and structures }\end{array}$ & $\begin{array}{l}\text { Situated and } \\
\text { disbributed } \\
\text { cognition }\end{array}$ & $\begin{array}{l}\text { Theories of knowledge } \\
\text { construction and } \\
\text { creation }\end{array}$ \\
\hline Collaboration & $\begin{array}{l}\text { Facilitation of } \\
\text { individual cognition }\end{array}$ & $\begin{array}{l}\text { Peripheral } \\
\text { participation }\end{array}$ & $\begin{array}{l}\text { Transformation of the } \\
\text { activity }\end{array}$ \\
\hline Technology & $\begin{array}{l}\text { Artefacts of } \\
\text { structuring }\end{array}$ & Social practice & $\begin{array}{l}\text { Artefacts of mediation } \\
\text { and transformation }\end{array}$ \\
\hline Methodology & Experimental & Ethnographic & Design research \\
& laboratories & $\begin{array}{l}\text { methods, discouse } \\
\text { analysis, observation. }\end{array}$ \\
& & Ecological validation
\end{tabular}

world dualism is replaced by the relationship between the whole and the parts. Instead of studying the mind as a receptacle, what emerges are the processes among the community of members that participate in a given physical and social context. The terminology of acquisition and accumulation is replaced by discourse, interaction, activity and participation. Knowledge does not exist in the world nor in the mind of the individual, but rather in the aspects of participation in the culture. (Brown, Collins, Duguid 1989; Lave-Wenger 1991)

Finally, there is a further, quite distinct, vision and one which seeks to overcome the model of participation. This is the model developed through the theories of knowledge construction proposed by Scardamalia and Bereiter (1994), and Engeström's model of expansive learning (1987) and Stahl's theory of group learning. (2003) We look at each of these briefly in order to see the range of concerns of these approaches. Drawing on these findings, we propose our own study as a source for reconsidering certain aspects of university teaching.

\section{Knowledge Construction and Learning}

Bereiter (2002) considers that the theories of learning based on the idea of the mind as a receptacle of ideas can tell us little about the knowledge that does not exist in the mind of the individual, and, therefore, that they are extremely limited when they speak of the advance in knowledge of organizations, and of knowledge as a product. The participative metaphor, according to Bereiter, is not much better. It enable us to understand how the "novice" becomes an "expert" by participating in cultural practices, but it 
says nothing about what occurs beyond these practices, when and how new knowledge is created. As a solution to these dilemmas, Bereiter offers the idea of knowledge construction, establishing a long the way a clear distinction between constructed knowledge and learning.

The concept of knowledge construction refers to the idea of collective work for the advancement and the creation of conceptual artefacts such as ideas, theories, models and entities (Popper's World 3). Learning, by contrast, is oriented towards change in the structures of individual knowledge. Knowledge construction goes beyond the metaphor of participation, since it establishes a distinction between knowledge used in a productive practice, and knowledge as an object (and also as a product) of this work. (Bereiter 2002)

Although the elements of World 3 are immaterial, Bereiter holds a pragmatic view. Bereiter and Engeström stress the idea of working with objects collaboratively, with ideas expressed and mediated through representations and multiple objects (artefacts). Collaboration is organised through activities centred on shared objects.

In both cases, individual activities are stressed. However, the individuals are not dealt with separately, but rather as part of a social network of the activities. They stress the joint-evolution of the individuals and the groups in order to overcome the individual acquisition dichotomy and the participative focus that considers unique the experience and the competence as practices and as tools.

Methodologically, the theory of knowledge construction is based on the idea of research design (Bereiter 2002; Collins 1999), or the methodology of the expansive cycle of development research. (Engeström 1987) These two approaches have many points in common. First, what defines the methodology is the objective: beyond an understanding of the current state of knowledge and practice, they support transformation and innovation. Secondly, both contain the idea that research should be undertaken in collaboration with practice. Thirdly, research is defined as intervention and is focused on the transformation of these practices. In both cases, the results serve as feedback for the system in order to generate new cycles of expansion. Engeström highlights the historical analysis of a particular activity in order to collaborate in its reflection and its internal contradictions.

In the case of Bereiter, collaboration is considered as a progressive discourse. The characteristics of progressive discourse in a specific community are the mutual advances made in comprehension, expanding the bases for discussion. The focus of progressive discourse is comprehension, and it sees knowledge as problematic, something that needs to be explained. Errors and misinterpretations are seen as opportunities to go forward. The participants negotiate their ideas with others. Each student is the member of a team in a learning community and, therefore, he or she produces knowledge.

Technology, according to Bereiter, serves to provide structure for this collaboration. Not only does it provide a space for sharing knowledge but it also has to act as a mediated environment for reflecting on and constructing knowledge. Indeed, Bereiter and Scardamalia's Knowledge Forum program was designed with this purpose in mind. In other words, it involves helping in the construction of knowledge based on the exploration of the interconnections between the different contributions of the participants. 
In short, the challenge faced by this tool is to construct a pedagogy based on collaborative knowledge construction in such a way that it is possible to involve students in seeking collaborative solutions to problems of understanding, so that the responsibility for success is shared between the students and the teacher rather than being something that is established previously by the teacher.

In the discourse related to knowledge construction, ideas, theories, hypotheses are treated as cultural artefacts and objects for research that can be argued over, improved and put to new uses as the participants become progressively engaged in their research.

\section{Group Learning and Individual Learning}

Stahl, in common with Bereiter, Scardamalia and Engeström, seeks to overcome the limitations of the acquisition and participation paradigms. The task does not involve seeking a path between the two, but rather moving to a different level - to that of the paradigm of knowledge creation. As pointed out above, there are many theories that recognize that the group is the place for knowledge construction and which emphasise the group nature of knowledge creation. However, they do not provide a detailed analysis of how groups actually learn.

In contrast with those theories that see learning as an individual objective and where collaboration is solely a means of supporting learning in the minds of individuals, and likewise in contrast with those theories that claim that learning is fundamentally social and only becoming internalized by the individual during a subsequent stage, Stahl (2005) proposes a perspective in which knowledge is the result of individual interactions at the group level. The group constructs knowledge that cannot be attributed to any one individual mind, and this is achieved through group discourse and it persists in physical and symbolic artefacts such as a text, a drawing or the particular language of the group.

Stahl shares the idea, together with Bereiter and Engeström, that collaboration is organized around objects and artefacts and also the idea of knowledge as object or product. For Stahl knowledge is the result of collaborative processes in which different interpretations are negotiated. Collaborative learning is a process of construction of meanings. (Stahl 2004) In a group, collaborative learning involves creating a network of meanings and individual learning in reconstructing a part of this network through one's own reasoning, words and texts.

Stahl's central proposal is that in small groups the knowledge that is created is not the sum of that of the individual participants. This knowledge is the fruit of group interactions. The individuals in a group, where the conditions favour the construction of this knowledge, do not have, either on entering or leaving it, the level of knowledge that the group achieves as a whole. In other words, group cognition occurs in a "situation" in which a set of oriented activities, mediating artefacts and the interpretative perspectives of its members converge.

This knowledge is manifest in the discourse that is constructed from the interactions. The notion of "group cognition" is not an ontological question in the sense of affirming the existence of a group mind that goes beyond the situated discourse, but 
rather a methodological question that analyzes the collaboration by taking the group and not the individual as the unit of analysis. The "construction of knowledge" consists in the modification of the meaning of the group that produces a word or participates in the discourse. (Stahl 2005, 3)

The knowledge of the group exceeds the knowledge that the individual group members have or might acquire, before, during and after the collaboration. (Stahl 2005, 10) The group develops an understanding that cannot be attributed to the participations of any one of the participants. The participations would have no sense if isolated from the discourse and the context of the activity in which they were made.

Knowledge can be constructed through group collaboration, interwoven with the individual acquisition of part of the knowledge, but independent of this acquisition. (Stahl 2005,10) It is through the divergences that arise between the individual interpretations of the group meaning or through the different connotations of the meaning, that the collaboration achieves its creative force. Such group knowledge is not always possible, and the results of collaboration are to a certain extent unpredictable. It is important, therefore, to attempt to establish and examine the conditions that make it possible.

Here it is important to ensure that the participants in the group are able to work well together, that they are willing to understand each other and that there is a good mix of skills among the members. Curricular materials need to be developed that encourage a good level of understanding based on collaborative interactions applied to open problems that cannot be solved by one individual but which require a shared understanding. The groups might be more effective in their "knowledge construction", if the members share interests, but have a varied range of experiences and perspectives. The technological tools need to be user friendly both for communication and for the representation of knowledge, and appropriately designed to overcome the limitations of face-to-face communication.

The educational task when seen from this perspective is transformed significantly. The challenge for the teacher is to create contexts in which meaningful interactions can occur and thereby achieve group cognition based around the solving of an open problem or the complex understanding of a particular theme. In turn, in order to take into consideration the construction of knowledge it is necessary to analyze carefully the registers of discourse that are constructed, the changes in group meaning, and the final product. To take into consideration the individual processes, it is possible to follow the register of the individual trajectories in the discourse and the changes that these undergo. The technological environment can provide written, meditated communication, which overcomes the limitations of face-to-face exchanges, as well as guaranteeing the register of the discourse in detail.

Stahl considers that the examination of these "jewels of interaction" is fundamental for understanding how group knowledge is formed, how shared meanings are generated, which subsequently remain as physical or symbolic artefacts. (Stahl 2004) 


\section{Innovation and Learning: The Theory of Expansive Learning}

Engeström begins with the study of activity theory in order to develop a model that describes complex systems of collective activity, based on which he explains what he terms the "Expansive Cycle" with which he, in turn, explains the development and transformation of present society. He uses this model to describe and define the activity of learning and to develop the process of expansive learning.

The origins of activity theory lie in the model of mediated action proposed by Vygotsky and developed further by Leontiev.

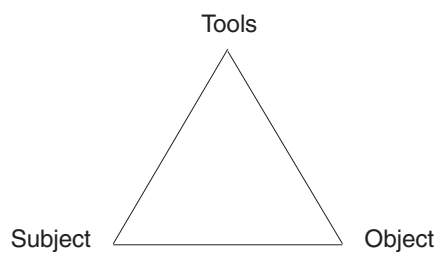

Fig.1

Drawing on these two theoretical bases, Engeström and Cole, expand Vygotsky's model of mediated action to form a model of human activity, describing the different components present in the phases of Leontiev's hierarchical structure of activity, resulting in the model included here as Figure 1. The objective of this model is to transcend the individual character of the activity, towards a collective character that represents better the social and historical-cultural elements present in all human activity.

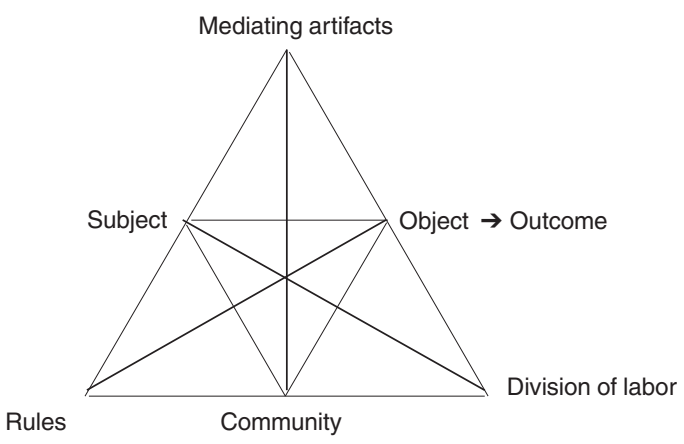

Fig .2

The object of the activity is what connects the individual actions to the collective activity, but the results in this system will not be momentary (goals) or situational, but rather the projected result consists in meanings that are socially important and in relatively new patterns of interaction. These results serve as a motive for the activity and give a broad meaning to the actions. 
From the historical-time perspective, Engeström discusses the differences between the time of an action and the time of an activity. In the case of an action, time is linear and finite while in that of an activity it is recurring and cyclical. These cycles are determined by the appearance of new structures or models for the activity undertaken. As such they are not predictable, or repeatable, as they are seen as historical facts immersed in a given context under certain given conditions. Given the generative character of these cycles, Engeström calls them expansive cycles of activity.

A system of collective activity is, by definition, a formation of multiple expressions. An expansive cycle is a re-orchestration of these expressions from the different points of view and perspectives of the participants of the collective. The expansive cycle within systems of collective activity can be seen as the equivalent of Vygotsky's "Zone of Proximal Development", as Engeström calls it. Engeström uses this model to describe the activity of learning, which he represents in his model of activity, as can be seen in Figure 3

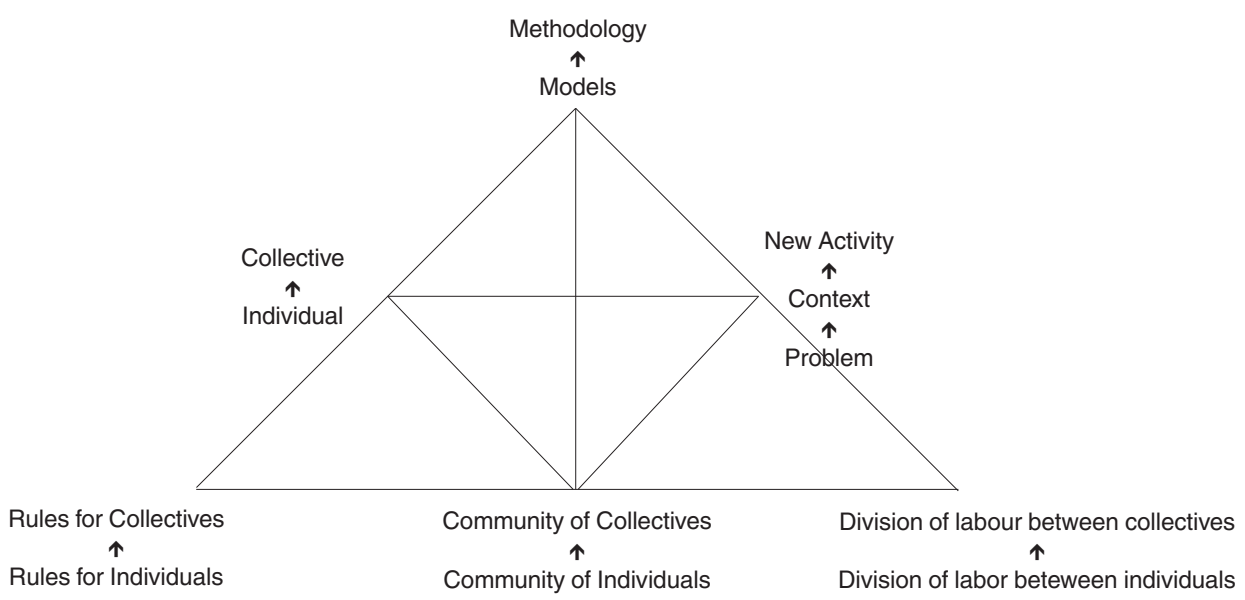

Fig. 3 Structure of the learning activity

The structure shown in Figure 3 represents the elements that need to be taken into consideration when studying the learning activity from a historical-cultural perspective, both individually and collectively.

The expansive cycles are underpinned by the idea that the internal contradictions of the dominant activity are the dynamic source of transition towards the formulation of the new activity. This idea was formulated by El'konin who proposes two phases that describe the ontogeny of each activity. In the first phase the relation is formed between the subject and the others, providing further evidence of the predominance of socioemotional and motivational aspects. In the second phase, the relation subject, object (goals) and instruments or mediating artefacts are formed, gradually presenting evidence of how the improvement in control over technical-operational aspects becomes predominant within the context of the activity. From this perspective, the contradic- 
tions appear when the control over the operational aspects acquired by the subject exceed the limits of the motive underlying the activity, initiating its expansive cycle and culminating in the creation of a new activity or a new structure of interaction within it.

Engeström stresses the importance of the historical-cultural contextualization within the development of and study of these systems of collective activity, where the unit of analysis should be the system of collective activity mediated by the artefacts and oriented to the objects. The system of collective activity and the expansive cycles are not only a tool to describe the elements and the processes that form part of a system of activity, but also serve as a frame of work and theoretical foundation of a research methodology, where it is necessary to integrate the different components of the activity and to identify historically the expansive cycles of the system. For this to occur, the researcher needs to become involved in the activity and participate in the creation of the new models or structures together with the group participants.

\section{CSCL in Higher Education}

The recent evolution of universities as institutions of society has seen them losing that sense of autonomy that used to characterize them. The production of knowledge, as pointed out at the beginning, is now taking place in many other settings and within many institutions. The university is thus losing its preeminence as a place for the construction of knowledge, and its role as the critical conscience of society. Increasingly it has become a functional entity meeting a range of needs that are outside its control. In other words, knowledge construction is moving away from the typical university environment towards much wider and more complex networks. The university does yet appear to be prepared to face up to these new challenges.

From the institutional perspective the universities continue to be trapped in the teacher-student-content triangle. Curriculum design and the organization of content in rigid, pre-established syllabuses continue to be the obsession of the teachers and the academic authorities. Organization along subject lines continues to be the model for administering the teaching. This organization results in fragmentation, a dispersion of the real interests of the students, superficial analysis or repetition of content throughout the degree course, and a concentration of the process around the figure of the teacher. It is, however, an organization that remains prevalent because it is easy to handle administratively and one that makes it easy to assign tasks to the teachers and spaces both real and even virtual. Frequently the design of virtual activities or courses reproduces the format of traditional class-based activities or courses. The organization by subject is also prevalent because there is an absence of creative planning in order to introduce new educational paradigms, which are known and even wished for by academics, in relation with cost structures that are adequate to maintain the economic viability of the universities. These circumstances favour a permanent pragmatic return, at times knowingly at others not, to the teacher-student-content triangle. 
Among the teachers an awareness has existed for many years of the importance of team work, of the importance of considering student interests. However, in practice, these perspectives have been visualized fundamentally in the framework of the classroom and of the traditional institutional organization of pre-established curriculum design and fragmentation into subjects. Similarly the idea of team work has been adopted only timidly and with little clarity, more as a tool to facilitate certain learning processes than as a process to create communities for the construction of knowledge. The notion of cooperative learning does not easily transcended into a notion of collaborative learning (Dillenbourg, 1999).

On the other hand, the great variety of educational paradigms and epistemological beliefs held by teachers is also significant, to the extent that in an attempt to unify criteria a new Tower of Babel is being erected. In the end what prevails is a paradigm of teaching based on a learning model. A paradigm of teaching that is more friendly and more aware but which retains its teaching focus.

Among the students it is significant to appreciate that in the main their epistemological beliefs lie, as current research is showing, within the paradigm of acquisition. Moreover, the students within a framework of an organization centred around subjects related only by the abstract concept of the curricular sequence, economize their efforts during each term according to the law of minimum effort, seeking the best mark possible and accumulating credits. The construction of systematic and in-depth knowledge is not the most noticeable feature of this student practice. The students learn to play the system and they play with the institutional structure in which they find themselves, at times with their genuine interests at heart, but more frequently to advance in the university process albeit without over committing themselves.

In relation with the evolution in university institutions it should be made clear that computer-supported collaborative learning set within the paradigm of "the creation of knowledge," is not just another educational strategy to be contemplated in the typical university setting. It provides a possible response to the construction of knowledge in the complex and wide networks that today characterize our society, beyond the traditional university frontiers. It is, or could be, a strategy for facing up sensibly and pertinently to the delocation of the processes of knowledge construction and management.

Moreover, in relation to the structures of the university institutions, it appears to be increasingly clear that a paradigm of "the creation of knowledge," such as that developed in earlier sections, requires or supposes a radical change in university organization. Centring the university process around the main interests of the students, centring the process of learning in communities of knowledge construction, is much more than an affirmation designed to make us feel innovative. It means eliminating as far as possible the fragmentation into subjects, modifying the current logic underlying curricular design, the way in which functions are assigned to teaching staff, many administrative practices, and in particular the handling of university timings. At this level of the university's structures, computer-supported collaborative learning cannot be seen as just another strategy. This form of learning establishes itself as central to the organization of the institution. The formation of communities of knowledge construction acquires 
pre-eminence over the organization of curricula and subjects. The link organized to extra-university networks becomes a fundamental element, at least in certain phases of the university course. The interaction between classroom-based learning and virtual education at the heart of computer-supported collaborative learning means a change in the organization of the timings within university life.

In relation to the teachers and the students, computer-supported collaborative learning as the "creation of knowledge" faces a powerful cultural inertia in which the acquisition paradigm has been predominant. Of course, at the level of the specific interaction between teachers and students, taking into consideration the limitations in the university structure mentioned above, the situation rests on the creation of collaborative environments which might become a reality at the level of the traditional classroom and virtual activities in a given space of time. Kirschner et al. (2004) propose a framework for the design of collaborative environments. Judging by research currently being conducted, the creation of these environments means facing many of the problems outlined above: a diverse range of contradictory epistemological beliefs, student mentality of minimum effort, and regressions in the teacher's role, among others. This complexity of the process points to the importance of examining the collaborative processes of knowledge construction taking as the unit of analysis the system of activity and the frontiers between the various systems of activity (of teachers, students, institutions, etc) as is provided for in Engeström's expansive learning model. (Lipponen et al. 2004, 38-39)

The design of computer-supported collaborative learning environments for the purpose of "knowledge construction" requires an integral effort that goes beyond the walls of the classroom or of the immediate educational context and which calls for a wider change in institutional practices and in the design of the university institution. The university faces the challenge of training for the construction and management of knowledge. Based on the conviction that computer-supported collaborative learning is one of the most promising perspectives for this task, it is essential that the university institution be revised as a whole on the basis of this perspective.

Research in this field is particularly varied and complex. Although it shares a fairly similar theoretical base, a closer examination of the research reveals that the panorama is much more diverse. What appears to be an area of work that is relatively well framed and homogenous is in fact a field of study that presents a great diversity of perspectives, focuses and interests. It is our belief that there exist certain tendencies in the research in this field that might be explained in terms of a cultural conception of learning and the diverse use of technology. As has happened on many occasions throughout the history of the introduction of computers in education (Gros 2000), the enthusiasm for the benefits and the effectiveness of computer-supported collaborative learning is frequent in the first publications on the subject. This enthusiasm has been seen in the literature on on-line learning, virtual training environments, distance learning, etc.

If we look beyond the specific problem of the design and the use of virtual learning environments, collaboration has been seen, in our opinion, from a somewhat superficial perspective. It appears that placing a group of students in a virtual forum is synony- 
mous with learning and collaboration, though this is something that has yet to be proved in most university practices. Initial studies in which collaboration has been examined from quantitative data of student interventions has, in most cases, provided little more than a general view of the quantities and flows of interactions without examining the content of the interaction and their consequences in terms of student learning.

The most problematic aspects start to reveal themselves in the research of Hallett and Cummins who note that "with most of the activities taking place in the forum with the class contributing, and with numerous messages from the teachers encouraging discussion, it has been hoped that interaction between the students would occur naturally. This is not what has happened." (1997: 105) Fischer et al. (2002) report that "in the set of studies undertaken it has been shown that efficiency of learning is rarely obtained by putting students together" (2002, 216). Generally, satisfaction with the way of learning is expressed but the results - in terms of quality of learning - are highly unsatisfactory (Kischner 2002, 11). Gunawardena $(1995,148)$ explains that the negative experiences he has observed in computer-supported collaborative learning are due much more to problems of communication between the participants than to the technical aspects of the programs or platforms used. For this reason, it seems important to study the conditions that favour collaborative learning and the design of environments that ensure this occurs. Other researchers focus their work on school or university organisation and most of these studies undertake microanalyses focusing on the interactions that take place in the classroom (traditional or virtual).

The difference in focus has a direct bearing on the units of analysis. In this sense, there are variations between studies that report the individual opinions of participants, interactions within the group, those with the other participating groups, the building of discourses, lines of argument, etc.

\section{Promoting Learning Practices at the University using CSCL}

Here, we are particularly interested in research conducted within the framework of the perspective afforded by knowledge construction. From this perspective, we are currently studying the conditions needed to promote the learning practices of university students using knowledge creation methodology in computer-supported environments. To date we have been conducting research using the Knowledge Forum program.

There are two main lines around which our studies have been conducted. On the one hand, the interest lies in studying the conditions required to promote the constructive process, the indicators that allow us to recognize the presence and the advance of the process through its various stages or phases, and finally, the appropriate type of evaluation for this process. Bearing in mind that we are operating in a structure of higher education in which traditionally it has been necessary to validate and evaluate, in some way, the student's knowledge. On the other hand, the use of technologies also presents its own uncertainties. What is the role of technologies within the process that we wish to generate, what role can they play in the processes of evolution, how can we 
determine their use within and/or outside the classroom in the context of activities oriented towards the construction of knowledge?

Below we briefly discuss the direction in which our research is leading us along these two lines, some of the conclusions that we have drawn and our future lines of research.

The theoretical frame of reference is based on the ideas of Bereiter, Engeström and Stahl which have been discussed above. Consequently, the research method of our study is that of educational design, based fundamentally on the proposals of Collins (1999). The use of this method implies seeing the research as a process that occurs in different stages. In the first stage of development various studies have been conducted in order to establish the conditions needed for undertaking the process of knowledge construction using the Kforum tool as technological support in a range of contexts. In terms of the use of technology, computers have been used both within and outside the classroom. In terms of the pedagogical approach, the methods used have also been varied: we have implemented some studies aimed at the solving of cases, some at the development of thematic lines and others at undertaking projects. Studies have also been conducted in which core subjects in two degree courses have been worked with. There has also been a varied integration of technology with the respective dynamics of the activities, this means that some teachers have integrated the use of technologies with the activities undertaken in each subject and, therefore, their use has been obligatory for the student. Others have opted to allow the student to choose between various activities among which one might be working with the Kforum. In such cases there was little or no integration between the activities undertaken in the classroom and those carried out on the Kforum.

It is not the objective of this article to provide a detailed report of the various studies undertaken. Our intention is to present our thoughts and on-going lines of study centred around three main subjects, in other words, the products of the results of the studies described above. First, the use of tools and criteria of evaluation were found to be necessary so as to allow both the teacher and student to monitor the process. Second, it is not entirely clear which aspects should be considered in order to ensure the correct use of the technologies developed as a support for the knowledge construction process. And finally, the article ponders the elements that, within a university context, condition the development of a collaborative attitude in the student, as a basis for knowledge construction.

Knowledge construction is a process, but in order for this process to be set in motion, a context is required in which there exists a high level of collaboration on the part of those who are participating in the activity. For this reason, throughout the research the need has become increasingly evident to have access to elements that allow us to know the level and notions of collaboration among the students during the undertaking of the activities. Moreover, our reflections on the need for criteria of evaluation in collaborative learning environments has been a further reason that has led us to seek tools that allow the actual implementation of processes of knowledge construction in the university. The need among teachers to invent formulae or strategies that 
allow them to establish a scale of values so as to be able to fulfill each academic requisite has meant that, in some cases, this element has been used as a means of motivating student participation. This raises the question as to whether it does not distort the meaning of the activity. We are currently developing a table of possible criteria for evaluation, using the ATK tool designed by the same creators as those that designed the Kforum. The aim of this table is to provide a guide that will allow, both the teacher and student, to observe and recognize the levels of collaboration and knowledge construction that they are developing during the activity.

Based on an analysis of the reasons that have led to the success or failure of the projects undertaken, we reflect here on the function that technology has within these activities. In this sense it can be said that if we focus on the technologies created within a specific theoretical framework, exemplified here by the Kforum, these have been created to operate largely at two levels. First, as a means of communication intended to allow interaction between the participants of an activity, transcending the limits of time and space. Moreover, they have been created basically to work at a second level which is that of mediating the process of knowledge construction, providing options and tools that distinguish them from other forums which would cover only the first level needs described above. These options or resources are intended to provide the support needed to reach the next zones of development in the process of knowledge construction. When we speak of such zones, we are referring both to the individual, as discussed by Vygotsky, and to the collective as discussed by Engeström. Reflecting on the function of the technology used in the processes of knowledge construction is important in determining the conditions under which they should be used.

Much has been said and written about the importance of the design of the activity or the task that seeks to promote collaboration, or knowledge construction or both, which after all are very closely linked. In our work we have seen that a careful design of the activity is essential for achieving the process that is sought. The design is fundamental but the role of the teacher is even more important. Similarly, much has been said about the need for teachers and students to change their roles, but when we speak of knowledge construction what does this role change really mean? What implications does it have for the knowledge and/or skills that the teacher who wishes to participate in this process has to handle? From our point of view, the research studies that have been carried out need to go beyond the simple affirmation that the teacher needs to know how to motivate, to understand the interests of his or her students, to have the skills to handle the group, and to know how to listen. These are important characteristics, and undoubtedly highly useful within the development process, but they might prove to be completely useless, if the teacher is not sustained by a notion of learning which is in agreement with the process that he wishes to promote. In other words, the teacher ought to have a very clear notion of the learning associated with the theoretical framework of knowledge building, since it is believed (a matter that we are currently debating) that the 
failures experienced in some of the projects have been due to the fact that the teachers might see the process of knowledge construction more as a methodological fact which is applied to the notion of learning as the final product of the acquisition of knowledge rather than as a notion of learning as the residual product of the process of knowledge construction. This is an aspect that we wish to examine in greater detail.

As can be seen, our research is beginning to identify possible future lines of study: From the microanalyses of collaboration and interaction, to the structural, organizational and cultural conditions for collaboration; from the analysis of the discourse interactions registered in the participations in the Knowledge Forum, to the more general analysis of the practices of collaboration of the students and their epistemological beliefs; from the context of the classroom, to the interaction between the activity systems (of teachers, institutional cases and students). The unit of analysis has shifted from being the individual or the group to that of the activity systems.

Although the research process highlights many defects in the original design of the learning environment that can be modified by the teacher at later stages (Kirschner et al 2004), it seems clear that the conditions required for collaborative knowledge construction are not only established within the frame of the classroom or the immediate learning environment. It is also certain that the central problem for collaboration is not the technological support, but rather the students' process of communication, their conception of the role of collaboration in their learning, their attitude and interest, the notions of learning held by teachers and students alike, as well as their respective epistemological beliefs.

A second stage in the research is foreseen as exploring at least two of the levels applying the perspective of activity systems forwarded by Engeström. The first is to examine in greater detail the characteristics of the immediate learning environment, in relation to the function of the technological support. Here it would seem important to examine the nature of the task (reorienting them according to the definition within knowledge creation and ensuring that the students appropriate them), the scaffolding for fostering processes of collaboration including the system of evaluation (offering more accurate scripts for undertaking a collaborative process in small groups), the conscious participation of the students in the research process (particularly as regards reflecting on their epistemological beliefs), and widening links with networks that are studying the same object. Similarly, there is a need to state the rules for asynchronous, communicationdiscussion via the Knowledge Forum. The latter combines two elements that intervene and it has been one of the most problematic matters in the handling of this support, while sharing documents and information through the same medium has not proved so problematic. The second level refers to the detection of practices and conceptions of collaboration between teachers, students, and the detection of the conditioning factors of the institutional culture around the process of computer-supported collaborative learning. 


\section{References}

Andriessen, J., Baker, M., \& Suthers, D. 2003 Arguing to learn : confronting cognitions in computer-supported collaborative learning environments. Dordrecht ; Boston: Kluwer Academic Publishers.

Barad, S.-D. T. 2000 From Practice Fields to Communities of Practice. In D.-L.S.E.Jonassen (Ed.), Theoretical Foundations of Learning Environments. Mahwah: Lawrence Erlbaum Associates: 25-26.

Barab, S. \& Squire, K. 2004 Design-Based Research: Putting a Stake in the Ground. The Journal of the learning sciences 13: 1-14.

Barnett, R. 2001 Los límites de la competencia. El conocimiento, la educación superior y la sociedad. Barcelona: Gedisa.

Bereiter, C. 2002a Design research for sustained innovation. Cognitives studies. Bulletin of the Japanes Cognitive Science Society 9:321-327.

Bereiter, C. 2002b Design research for sustained innovation. Cognitives studies. Bulletin of the Japanes Cognitive Science Society 9:321-327.

Bereiter, C. 2002c Education and mind in the knowledge age. London: LEA.

Brown, J. S., Collins, P. \& Duguid, P. 1989 Situated cognition and the culture of learning. Educational Researcher 18:32-42.

Bruffee, K. 1995 Sharing Our Toys: Cooperative learning versus collaborative learning. Change 27:12-18.

Bruner, J. S. 1966 Toward a theory of instruction. Cambridge MA: The Belnap Press of Harvard University press.

Capra, F. 1998 La trama de la vida. Barcelona: Anagrama.

Castells, M. 1997 La era de la información. Madrid: Alianza.

Chan, C. K. K. \& VanAalst, J. 2003 Assessing and scaffolding knowledge building: Pedagogical knowledge building principles and electronic portfolios. In Wasson. B \& Hoppe, U. (Ed.), Designing for Change in Networked Learning Environments. Dordrecht: Kluwer Academic Publishers, 21-30.

Collins, A., Joseph, A., \& Bielaczic, K. 2004 Design research: Theoretical and methodological issues. The Journal of the Learning Sciences, 13: 15-42.

Davies, D. 2002 La competencia del aprendizaje permanente en el siglo XXI: un programa. In R.e.a.Teare \& S. and (Eds.), Organizaciones que aprenden y formación virtual Barcelona: Gedisa: 91-108.

De Jong, F. e. a. 2002 Computer supported collaborative learning in university and vocational education. In Korschmann, T., Hall, R. \& Miyake, N. (Eds.), CSCL 2: Carrying Forward the Conversation, Mahwah, NJ.: Lawrence Erlbaum Associates: 111-127.

Derry, S. J. \& Hawkes, L.W. 1993 Local cognitive modelling of problem solving behavior:an application of fuzzy theory. In Lajoie, S.P. \& Derry, S.J. (Eds.), Computers as Cognitive Tools. Malwah, NJ., Lawrence Erlbaum Associates: 107-140.

DeVillar, R. A., Faltis, C., \& Cummins, J. 1994 Cultural diversity in schools: From Rhetoric to Practice. Albany: State University of New York Press.

Dillenbourg, P. 1999a Collaborative Learning. Cognitive and Computational Approaches. Amsterdam: Pergamon.

Dillenbourg, P. 1999b Introduction: What do you mean by "collaborative learning"? In Dillenbourg, P. (Ed.), Collaborative learning. Cognitive and Computational Approaches Amsterdam: Pergamon: 1-19.

Dillenbourg, P. \& Self, J.A. 1992 Computational approach to socially distributed cognition. European Journal of Psychology of Education 7:352-373.

Duffy, T \& Cunningham, D. 1996 Constructivism: Implications for the design and delivery of Instruction. In Jonassen, D. (Ed.), Handbook of Research for Educational Communications and Technology. New York: Prentice House: 170-199. 
Engeström, Y. 1999 Activity theory and individual and social transformation. In Engeström, Y, Miettinen, R. \& Punamäki, R.L. (Eds.), Perspectives on Activity Theory Cambridge, UK: Cambridge University Press: 19-38.

Engeström, Y. 1987 Learning By Espanding: An Activity-Theoretical Approach to Developmental Research. Helsinky: Orienta-Konsultit Oy.

Engeström, Y., Miettinen, R. \& Punamaki, R.L. (Eds.) 1999 Perspectives on Activity Theory. Cambridge: Cambridge University Press.

Gros, B. 2002 Constructivismo y diseño de entornos virtuales de aprendizaje. Revista de la Educación 328: 225-247.

Gros,B \& Romañá,T. 2004 Ser Profesor. Barcelona: Octaedro.

Hakkarainen, K., Lipponen, L. \& Jarvela, S. 2001 Epistemology of inquiry and computer supported collaborative learning. In Koshcmann, T., Hall, R. \& Miyake, N. (Eds.) CSCL 2: Carrying Forward the Conversation. Malawak, NJ: Lawrence Erlbaum Associates.

Hansen, T., Dirchinick, L. \& Lewis, R. 1999 Using telematics for collaborative knowledge construction. In.Dillenbourg, P. (Ed.) Cognitive and Computational Approaches. Oxford: Pergamon: 169-196.

Himanen, P. 2002 La ética del hacker y el espiritu de la era de la información. Barcelona: Destino. Hutchins, E. 1996 Cognition in the Wild. Cambridge,MA: MIT Press.

Jonassen, D. \& Rohrer Murphy, L. 1999 Activity theory as a framework for designing constructivist learning environments. Educational Technology Research and Development 47: 61-79.

Jonassen, D.H., Peck, K.L., Wilson, B.G. 1999. Learning with Technology: A Constructivist Perspective. Upper Saddle River, NJ: Merrill.

Kirscher, P., Strijbos, J.W. \& Kreijns, K. 2003. Designing integrated electronic collaborative learning environments. In .Jochems, W, van Mertrienboer, J. \& Koper, R. (Eds.), Integrated E-learning: Implications for Pedagogy, Technology and Organization, London: Taylor \& Francis: 24-38.

Kirschner, P. A., Martens, R. L. \& Strijbos, J. W. 2004 CSCL in higher education? In Strijbos, J.W., Kirschner, P.A. \& .Martens, R.L. (Eds.) What We Know About CSCL. And Implementing It in Higher Education. Dordrecht, NL: Kluwer Academic Publishers: 53-85.

Koschmann, T. D. 1994 Computer Support for Collaborative Learning. Hillsdale, NJ: Lawrence. Erlbaum Associates.

Koschmann, T. 2003a CSCL, argumentation, and deweyan inquiry: argumentation is learning. In Andriessen, J., Baker, M. \& Suthers, D. (Eds.) Arguing to learn : confronting cognitions in computer-supported collaborative learning environments. Dordrecht: Kluwer Academic Publishers: 261-269.

Koschmann, T. e.a. 2003b Problematizing the problem. In Wason, B., Ludvegsen, S. \& Hoppe, U. (Eds.) Designing for Change in Networked Learning Environments. Dordrecht: Kluwer Academic Publisher: 37-46.

Lave, J., \& Wenger, E. 1991 Situated learning: Legitimate peripheral participation. Cambridge, MA: Cambridge University Press.

Leontiev, A. N. 1978 Actividad, conciencia y personalidad. Buenos Aires: Ciencias del Hombre.

Lipponen, L., Hakkarainen, K. \& Paavola, S. 2004 Practices and orientations of CSCL. In Strijbos, J.W., Kirschner, P.A., \& .Martens, R.L. (Eds.) What we know about CSCL. And implementing it in higher education. Dordrecht, NL: Kluwer Academic Publishers: 53-85.

Luria, A. R. 1987 Desarrollo histórico de los procesos cognitivos. Madrid: Akal.

Pea, R. 1994 Seeing what we build together: Distributed multimedia learning environments for transformative learning. Journal of Learning Sciences 3:283-298.

Reeves, T.C., Herringston, J. \& Oliver, R. 2004 A development research agenda for on line collaborative learning. Educational Technology Research \& Development 52:53-66.

Rogoff, B. 1993 Aprendices del pensamiento. Barcelona: Paidós. 
Roschelle, J. \& Teasley, S. D. 1995 The construction of shared knowledge in collaborative problem solving. In O'Malley, C. (Ed.) Computer-Supported Collaborative Learning. Berlin: Springer-Verlag: 69-197.

Salomon, G. 1993 No distribution without individual's cognition:A dynamic interactional view. In G.Salomon (Ed.) Distributed Cognitions. New York: Cambridge University Press: 111-138.

Scardamalia, M. \& Bereiter, C. 1994 Computer support for knowledge-building Communities. Journal of the Learning Sciences 3:256-283.

Scardamalia, M. 2002 Collective cognitive responsibility for the advancement of knowledge. In Smith, B. (Ed.), Liberal Education in a Knowledge Society. Chicago: Open Court: 67-98.

Schön. D. A. 1983 The Reflective Practitioner: How Professionals Think in Action. New York: Basic Books.

Stahl, G. 2005 Group cognition in computer assisted collaborative learning. Journal of Computer Assisted Learning. Retrieved from www.cis.drexel.edu/faculty/gerry/ publications/journals/index.html

Stahl, G. 2004 Building collaborative knowing: Elements of a social theory of CSCL. In Strijbos, J.W., Kirschner, P.A., \& Martens, R.L. (Eds.) What We Know About CSCL. And Implementing It in Higher Education. Dordrecht, NL: Kluwer Academic Publishers: 53-85.

Stahl, G. 2002 Contributions to a theoretical framework for CSCL. In Stahl, G.(Ed.), Computer Support for Collaborative Learning: Foundations for a CSCL Community: Proceedings of CSCL 2002. Hillsdale: Lawrence Erlbaum Associates: 62-71.

Stahl, G. 2003 Negotiating Shared Knowledge in Asynchronous Learning Networks: Paper presented at the Hawaii International Conference on System Sciences 36.

Strijbos, J.W., Kirschner, P. \& Martens, R.L. 2004 What We Know About CSCL and Implementing It In Higher Education. Norwell: Kluwer Academic Press.

Vygotsky, L. S. 1989 El desarrollo de los procesos psicológicos superiores. Barcelona: Critica.

Wenger, E. 2001 Comunidades de práctica. Aprendizaje, significado e identidad. Barcelona: Paidós. 